\title{
High Resolution Imaging to Determine the Effect of Vitamin D and Bone; Mini Review
}

\author{
Hassan Alshamrani* \\ Radiological Sciences Department, Najran University, Saudi Arabia
}

Submission: August 20, 2019; Published: September 06, 2019

*Corresponding author: Hassan Alshamrani, Radiological Sciences Department, College of Applied Medical Sciences, Najran University, Saudi Arabia

\section{Abstract}

High resolution imaging can provide in depth understanding of the bone quality. Vitamin D has been used to improve bone in health in patient with high risk of vitamin D deficiency. This review provides some information about determining the effect of vitamin D on bone quality as measured by high resolution peripheral imaging.

Keywords: Bone quality; Vitamin D deficiency; Health; Patient; High resolution peripheral imaging; Calcium supplements; Bone densitometry; Supplementation; Microarchitecture; Peripheral imaging; Hyperparathyroidism

\section{Introduction}

Most of the literature investigating the optimal level of vitamin D is based on its effects on bone health and more specifically on determining the effect of conventional and high doses of vitamin D supplementation on bone density. Several studies have investigated the effect of conventional or a single high dose vitamin D on bone density. The baseline level of serum $25(\mathrm{OH}) \mathrm{D}$ may be an important determinant for the effectiveness of vitamin D supplements in improving bone density. Overall, two systematic reviews and meta-analysis of the effect of vitamin D supplements on bone density in both the elderly and in adolescents indicate that vitamin D supplementation in a population with an adequate level of vitamin D is unlikely to improve bone density Reid \& Winzenberg et al. [1,2]. Nevertheless, vitamin D combined with calcium supplements for the prevention of bone loss in elderly populations has been recommended Tang et al. [3]. A common issue in reporting the effect of vitamin D on bone density is the fact that most studies have relied on areal BMD (as measured by DXA which is just surrogate measure of bone density) to determine the effect of the treatment. More advanced techniques in bone densitometry such as high-resolution imaging may lead to a better understanding of the relationship between vitamin $\mathrm{D}$ and bone structure

\section{Method}

A focused search was conducted utilizing quality resources, e.g., PubMed, Ovid Medline and Cochrane library to locate the relevant papers which investigated the effect of vitamin
D supplementation on bone density and microstructure as measured by Peripheral Quantitative Computed Tomography (pQCT) or High Resolution Peripheral Quantitative Computed Tomography (HRpQCT).

\section{Literature Review}

More advanced techniques in bone densitometry such as peripheral imaging has recently been introduced and may lead to a better understanding of the relationship between vitamin $\mathrm{D}$ and bone structure. For instance, in a recent trial of horse jockeys, $400 \mathrm{IU}$ of vitamin D supplementation and $800 \mathrm{mg}$ of calcium in a population of those with sufficient vitamin D were found to significantly improve several pQCT parameters at the proximal tibia (66\%) Silk et al. [4] but no significant positive effect was detected at the radius in young male jockeys Silk et al. [4]. However, the result of this trail may not be generalisable since the participants were professional jockeys who have weight restrictions plus the fact that the study contained a small sample size $(n=17)$. The literature search revealed no other trial investigating the effect of vitamin d on bone health using pQCT.

The recent utilisation of HR-pQCT may potentially lead to an even deeper understanding of the effect of vitamin D supplementation on bone microstructure and quality. However, trials studying the effects of vitamin D using HR-pQCT are very limited in number due to its cost and very recent availability. Of those which have been found in the literature search, Boyd et al. [5] investigated the relationship between serum 25(OH)D and 
HR-pQCT parameters in three groups with different vitamin D levels (low $=>75 \mathrm{nmol} / \mathrm{L}$, medium $=75-175 \mathrm{nmol} / \mathrm{L}$ and high $>175 \mathrm{nmol} / \mathrm{L}$ ). The authors reported no significant relationship between serum 25(OH) D and bone microarchitecture parameters. In another cross-sectional study in patients with primary hyperparathyroidism, vitamin D deficiency and insufficiency was not found to significantly affect volumetric bone density, bone microarchitecture, or strength Walker et al. [6].

However, the cross-sectional design of this study should be noted in considering the results. In another recent trial on the effect of high doses of vitamin D $(50,000 \mathrm{IU} /$ week for 24 weeks) on HR-pQCT parameters in juvenile-onset systemic lupus erythematosus (JoSLE) patients who were mostly vitamin D insufficient, a significant increase in trabecular number and a significant decrease in trabecular separation was reported in the vitamin D group Lima et al. [7]. A recent proposal by Burt et al. [8] to administer 3 different doses of vitamin D (1000 IU/day or $4000 \mathrm{IU} /$ day or 10,000 IU/day) over 3 years and to use HRpQCT to longitudinally determine any change in bone density and microstructure looks promising to enhance our understanding of the effect of various doses of vitamin D on bon.

\section{Conclusion}

In conclusion, high resolution imaging looks promising in deepening our understanding of the effect of vitamin $d$ on bone micro structure but more trials are a warrant.

\section{References}

1. Reid IR, Bolland MJ, Grey A (2014) Effects of vitamin D supplements on bone mineral density: a systematic review and metaanalysis. The Lancet 383(9912): 146-155.

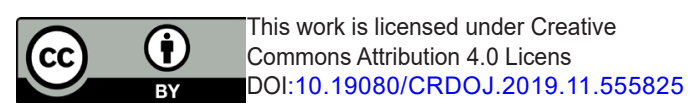

2. Winzenberg T, Powell S, Shaw KA, Jones G (2011) Effects of vitamin D supplementation on bone density in healthy children: systematic review and meta-analysis. British Medical Journal 342: 9.

3. Tang BM, Eslick GD, Nowson C, Smith C, Bensoussan A (2007) Use of calcium or calcium in combination with vitamin D supplementation to prevent fractures and bone loss in people aged 50 years and older: a meta-analysis. Lancet 370(9588): 657-666.

4. Silk LN, Greene DA2, Baker MK, Jander CB (2017) The effect of calcium and vitamin D supplementation on bone health of male Jockeys. J Sci Med Sport 20(3): 225-229.

5. Boyd SK, Burt LA, Sevick LK, Hanley DA (2015) The relationship between serum $25(\mathrm{OH}) \mathrm{D}$ and bone density and microarchitecture as measured by HR-pQCT. Osteoporos Int 26(9): 2375-2380.

6. Walker MD, Nishiyama KK, Zhou B, Cong E, Wang J (2016) Effect of low vitamin $\mathrm{D}$ on volumetric bone mineral density, bone microarchitecture, and stiffness in primary hyperparathyroidism. J Clin Endocrinol Metab 101: 905-913.

7. Lima GL, Paupitz JA, Aikawa NE, Alvarenga JC, Pereira RMR (2018) A randomized double-blind placebo-controlled trial of vitamin D supplementation in juvenile-onset systemic lupus erythematosus: positive effect on trabecular microarchitecture using HR-pQCT. Osteoporos Int 29(3): 587-594.

8. Burt LA, Gaudet S, Kan M, Rose MS, Billington EO (2018) Methods and procedures for: A randomized double-blind study investigating dosedependent longitudinal effects of vitamin D supplementation on bone health. Contem Clin Trials 67: 68-73.

Your next submission with Juniper Publishers
will reach you the below assets
- Quality Editorial service
- Swift Peer Review
- Reprints availability
- E-prints Service
- Manuscript Podcast for convenient understanding
- Global attainment for your research
- Manuscript accessibility in different formats
( Pdf, E-pub, Full Text, Audio)
- Unceasing customer service
Track the below URL for one-step submission
https://juniperpublishers.com/online-submission.php

